\title{
Partitioning of the elastic work of inspiration in patients with COPD during exercise
}

\author{
P. Sliwinski*, D. Kaminski*, J. Zielinski*, S. Yan+
}

Partitioning of the elastic work of inspiration in patients with COPD during exercise. $P$. Sliwinski, D. Kaminski, J. Zielinski, S. Yan. OERS Journals Ltd 1998.

ABSTRACT: During exercise, dynamic hyperinflation-induced intrinsic positive endexpiratory pressure (PEEPi) and decreased dynamic lung compliance $(C \mathrm{~L}, \mathrm{dyn})$ of patients with chronic obstructive pulmonary disease (COPD) increase the elastic work of inspiration $(W \mathrm{i})$ more than would be predicted from the increase in tidal volume $(V T)$. This contributes significantly to their exertional breathlessness.

In 10 stable patients with COPD, the dynamic $W$ i was measured during incremental bicycle exercise to exhaustion. The total $W$ i was then partitioned into the portion required to overcome PEEPi $(W i, P E E P i)$ and nonPEEPi elastic load $(W i$,nonPEEPi). The latter is used to overcome the increase in the total respiratory system elastance during inflation.

From resting breathing to peak exercise, Wi more than doubled $(p<0.001)$. This increase was largely due to $W$ i,PEEPi, which significantly rose from $1.7 \pm 0.3$ to $5.3 \pm$ $0.8 \mathrm{~L} \cdot \mathrm{cmH}_{2} \mathrm{O}^{-1}(\mathrm{p}<0.001)$. In comparison, $W \mathrm{i}$,nonPEEPi increased from only $3.0 \pm 0.4$ to $5.1 \pm 0.5 \mathrm{~L} \cdot \mathrm{cmH}_{2} \mathrm{O}^{-1}(\mathrm{p}<0.01)$. Consequently, $W \mathrm{i}, \mathrm{PEEPi}$ as a fraction of total $W \mathrm{i}$ increased from $35.5 \pm 5.6$ to $51.0 \pm 3.3 \%(p<0.02)$. In addition, the measured $W$, nonPEEPi at peak exercise, when expressed as a percentage of its value during resting breathing, was $25 \%$ more than that predicted from the increase in $V \mathrm{~T}$ alone. Assuming a constant chest wall compliance, this can be attributed to the exercise-induced decrease in $C \mathrm{~L}, \mathrm{dyn}$, which was $0.27 \pm 0.04$ and $0.17 \pm 0.02 \mathrm{~L} \cdot \mathrm{cmH}_{2} \mathrm{O}^{-1}(\mathrm{p}<0.01)$, respectively, during resting breathing and peak exercise.

In conclusion, the dynamic hyperinflation-induced intrinsic positive end-expiratory pressure is more important than the increase in tidal volume in raising the work of inspiration during exercise in patients with chronic obstructive pulmonary disease; the decrease in dynamic lung compliance plays a definite but less important role. Eur Respir J 1998; 11: 416-421.
*Institute of Tuberculosis and Lung Diseases, Warsaw, Poland. ${ }^{+}$Meakins-Christie Laboratories, McGill University and Montreal Chest Institute, Royal Victoria Hospital, Montreal, Canada

Correspondence: S. Yan

Meakins-Christie Laboratories

McGill University and Montreal Chest Institute

3626 St. Urbain Street

Montreal

Quebec

Canada H2X 2P2

Fax: 15143987483

Keywords: Dynamic hyperinflation

dynamic lung compliance

elastic work of breathing

intrinsic positive end-expiratory pressure

Received: April 71997

Accepted after revision December 11997

The study was supported by the Polish State Research Committee and Montreal Chest Institute
During exercise, the elastic work of inspiration $\left(W_{\mathrm{i}}\right)$ in healthy subjects increases mainly due to an increase in tidal volume $(V \mathrm{~T})$. This is partly compensated for by the fall in end-expiratory lung volume (EELV) as a result of exercise-induced recruitment of expiratory muscles [1-3]. In patients with chronic obstructive pulmonary disease (COPD), the increase in $W \mathrm{i}$ is more than would be predicted from the increase in $V \mathrm{~T}$ during exercise [4], and contributes significantly to the sense of breathing effort and reduced exercise capacity. Two additional factors play a crucial role in increasing $W_{\mathrm{i}}$ in these patients. Firstly, due to expiratory airflow limitation, dynamic hyperinflation is almost inevitable during exercise, leading to an increased EELV and intrinsic positive end-expiratory pressure (PEEPi) [5-8] in spite of expiratory muscle activity. PEEPi behaves as an inspiratory threshold load and needs to be overcome before inspiratory flow can be generated [9], therefore, it significantly increases $W_{\text {i }}$ for a given ventilation. Secondly, the increased frequency of breathing during exercise results in a decreased dynamic lung compliance $(C \mathrm{~L}, \mathrm{dyn})$ in patients with COPD [10, 11], which also contributes to the increase in $W$ i under dynamic conditions.
How PEEPi and changes in $C \mathrm{~L}$,dyn in patients with COPD quantitatively contribute to an increase in $W$ i during exercise has not been described in detail. The purposes of the present study were, therefore, to quantify, in a group of clinically stable patients with COPD, the increase in $W$ i during exercise, and to partition it into the contributions from the increased PEEPi and from the decreased $C \mathrm{~L}$,dyn, in order to better understand inspiratory mechanics during exercise in this patient population.

\section{Methods}

\section{Patients}

A total of 10 patients with severe COPD (nine males and one female) in clinically stable conditions volunteered for the experiment. Clinically stable COPD is defined as having the medical history and signs of chronic airway obstruction but without acute exacerbation within 1 month prior to the study. Patients with evidence of cardiovascular disease, systemic disease and neuromuscular disease which are likely to affect exercise performance 
Table 1. - Patient characteristics and lung function test results

\begin{tabular}{|c|c|c|c|c|c|c|c|c|c|c|c|}
\hline $\begin{array}{l}\mathrm{Pt} \\
\text { No. }\end{array}$ & $\begin{array}{c}\text { Age } \\
\mathrm{yr}\end{array}$ & $\begin{array}{l}\text { W } \\
\mathrm{kg}\end{array}$ & $\begin{array}{l}\mathrm{H} \\
\mathrm{cm}\end{array}$ & $\begin{array}{c}\text { FEV1 } \\
\text { L }\end{array}$ & $\begin{array}{c}\mathrm{FEV} 1 / \mathrm{FVC} \\
\%\end{array}$ & $\begin{array}{c}R \text { aw } \\
\mathrm{cmH}_{2} \mathrm{O} \cdot \mathrm{L}^{-1} \cdot \mathrm{s}^{-1}\end{array}$ & $\begin{array}{c}\text { TLC } \\
\text { L }\end{array}$ & $\begin{array}{c}\text { FRC } \\
\text { L }\end{array}$ & $\begin{array}{c}\mathrm{RV} \\
\mathrm{L}\end{array}$ & $\begin{array}{l}\mathrm{Pa}_{\mathrm{a}, \mathrm{O}_{2}} \\
\mathrm{kPa}\end{array}$ & $\begin{array}{c}\mathrm{Pa}_{\mathrm{a}, \mathrm{CO}_{2}} \\
\mathrm{kPa}\end{array}$ \\
\hline 1 & 58 & 76 & 160 & $0.76(33.3)$ & 0.42 & 10.1 & $4.37 \quad(90.4)$ & $3.66(137.4)$ & $2.72(146.6)$ & 10.2 & 5.9 \\
\hline 2 & 62 & 68 & 168 & $0.92(31.0)$ & 0.37 & 12.8 & $8.50(134.0)$ & 6.49 (191.4) & $5.56(240.2)$ & 8.0 & 6.7 \\
\hline 3 & 67 & 68 & 164 & 0.44 (16.0) & 0.25 & 7.2 & 7.89 (131.0) & $6.72(200.1)$ & $5.40(223.7)$ & 10.1 & 5.9 \\
\hline 4 & 64 & 78 & 180 & $1.32(38.6)$ & 0.46 & 4.6 & $5.60 \quad(76.7)$ & 4.27 (115.7) & 2.69 (106.9) & 7.7 & 6.9 \\
\hline 5 & 57 & 87 & 169 & $1.10(34.0)$ & 0.31 & 3.6 & (73.3) & $2.25 \quad(67.8)$ & $1.55 \quad(85.8)$ & 10.8 & 5.6 \\
\hline 6 & 56 & 55 & 158 & $0.84(37.1)$ & 0.35 & 7.0 & $6.41(138.1)$ & $4.45(171.4)$ & 3.69 (211.8) & 8.2 & 5.6 \\
\hline 7 & 41 & 54 & 169 & $0.80(32.0)$ & 0.30 & 7.7 & $9.22(143.6)$ & $7.86(242.4)$ & 6.65 (348.7) & 8.2 & 5.6 \\
\hline 8 & 47 & 65 & 170 & $0.88(25.6)$ & 0.29 & 8.6 & $7.80(121.4)$ & $6.30(192.1)$ & $5.08(254.7)$ & 7.2 & 5.9 \\
\hline 9 & 62 & 83 & 172 & $0.96(30.9)$ & 0.25 & 7.7 & $8.40(126.1)$ & $6.24(178.5)$ & 4.71 (197.3) & 9.0 & 5.9 \\
\hline 10 & 59 & 70 & 170 & 0.68 (21.9) & 0.25 & 9.4 & 8.87 (136.4) & 7.33 (214.4) & 6.23 (271.6) & 7.7 & 6.3 \\
\hline Mean & 57 & 70 & 168 & $0.87(30.0)$ & 0.32 & 7.9 & $7.22(117.1)$ & $5.56(171.1)$ & 4.43 (208.7) & 8.8 & 6.0 \\
\hline SEM & 8 & 3 & 2 & $0.07 \quad(2.2)$ & 0.02 & 0.8 & 0.54 & $0.56 \quad(16.2)$ & $0.53 \quad(25.0)$ & 0.4 & 0.1 \\
\hline
\end{tabular}

Values are presented as absolute values with percentages of predicted values in parenthesis. Pt: patient; W: body weight; H: height; FEV1: forced expiratory volume in one second; FVC: forced vital capacity; Raw: airway resistance; TLC: total lung capacity; FRC: functional residual capacity; $\mathrm{RV}$ : residual volume. $\mathrm{Pa}, \mathrm{O}_{2}$ : arterial oxygen tension; $\mathrm{Pa}_{\mathrm{a}} \mathrm{CO}_{2}$ : arterial carbon dioxide tension. Lung functions were measured in a body plethysmograph. Patients No. 4 and 5 also have restrictive pulmonary changes. $1 \mathrm{kPa}=7.52 \mathrm{mmHg}$.

were excluded. Patient characteristics and lung function test results are given in table 1 . All patients gave their informed consent to the protocol which had been explained to them in detail necessary for their understanding. The experimental protocol was approved by an appropriate institutional research ethics committee.

\section{Measurements}

Respiratory flow was measured by a Fleisch No. 2 pneumotachograph (Fleisch, Lausanne, Switzerland) and a differential pressure transducer. Mouth pressure $(P \mathrm{~m})$ was measured by a differential pressure transducer which was connected to the mouthpiece. Oesophageal and gastric pressures ( $P_{\text {oes }}$ and $P$ ga, respectively) were measured conventionally by two additional differential pressure transducers attached to balloon-tipped catheters. One was placed in the lower third area of the oesophagus and the other in the stomach, to reflect the changes in pleural and abdominal pressures $(P \mathrm{pl}$ and $P \mathrm{ab})$, respectively. The oesophageal balloon was inflated with $0.5 \mathrm{~mL}$ of air and its position was carefully adjusted so that the amplitudes of $P_{\mathrm{oes}}$ and $P_{\mathrm{m}}$ were equal during an airway occlusion test and car- diogenic artifacts were minimized. The gastric balloon was inflated with $1.0 \mathrm{~mL}$ of air. End-tidal carbon dioxide tension $\left(P \mathrm{ET}, \mathrm{CO}_{2}\right)$ was measured using a $\mathrm{CO}_{2}$ analyser whose inlet was inserted into the mouthpiece. During exercise, arterial oxygen saturation $\left(\mathrm{Sa}_{\mathrm{a}} \mathrm{O}_{2}\right)$ and electrocardiogram (ECG) measurements were continuously monitored. Arterial blood pressure was measured at the end of each workload. Mot-ions of the rib cage and abdomen during breathing were measured by two respitrace bands placed on the upper rib cage and the abdomen. These signals were used for estima-ting expiratory muscle contribution to $P_{\text {oes }}$ baseline during quiet breathing [12, 13].

\section{Protocol}

The patients were seated on an electronically braked ergometer (Ergo-Metrics 800; Ergo-Line GmbH + Co KG, Bitz, Germany) with their body tilted slightly forward and their arms supported by the handle of the ergometer in order to maintain an unchanged posture throughout the experiment. The patients breathed through a mouthpiece while wearing a noseclip. No patient took long-lasting bronchodilators and all refrained from taking coffee or bronchodilators for at least $4 \mathrm{~h}$ before the experiment. At the beginning of the experiment, patients were instructed to breathe quietly on the bicycle without pedalling for $\sim 5$ min to become accustomed to the breathing circuit. In the last 2 min of this adaptation, quiet breathing data were recorded. The patients then performed an incremental bicycle exercise starting at a workload of 10 or $20 \mathrm{~W}$. The workload was progressively increased every minute by 10 or $20 \mathrm{~W}$ until symptom limitation. At the end of quiet breathing and the end of each level of exercise, an inspiratory capacity (IC) inspiration was performed by "making a further maximal effort on top of a maximal inspiration" [6, 14].

\section{Data analysis}

The respiratory flow, $P_{\text {oes }}, P$ ga, respitrace signals, $S_{\mathrm{a}}, \mathrm{O}_{2}$, and $P$ ET, $\mathrm{CO}_{2}$ were all amplified, digitized at $100 \mathrm{~Hz}$, and stored in a computer. The actual sampling frequency was sometimes increased up to $1,000 \mathrm{~Hz}$ when necessary by linear extrapolation, in order to analyse fast events, such as the development of $P_{\text {oes }}$ during the initial part of inspiration. The signals for the last five breaths at a given workload were averaged for further analysis. $V \mathrm{~T}$, breathing frequency, minute ventilation $\left(V^{\prime} \mathrm{E}\right)$, and duty cycle were derived from the flow signal. Change in EELV $(\triangle \mathrm{EELV})$ was measured by calculating the magnitude of IC, assuming the decrease in IC equals the increase in EELV during exercise [5-8]. The change in end-inspiratory lung volume $(\triangle \mathrm{EILV})$ was calculated as $\triangle \mathrm{EELV}+V \mathrm{~T}$. $C$,dyn was measured by dividing $V \mathrm{~T}$ by the difference in $P$ oes values at the beginning and end of inspiratory flow.

Figure 1 shows schematically the method used to calculate and partition the elastic work of inspiration. In this figure, the static volume-pressure relationship of the chest wall (the straight line passing points F, E, D) is shown. It was assumed that this relationship is linear [15] and its slope in patients with COPD is comparable to that obtained in healthy subjects [16-18]. Thus, the slope of 


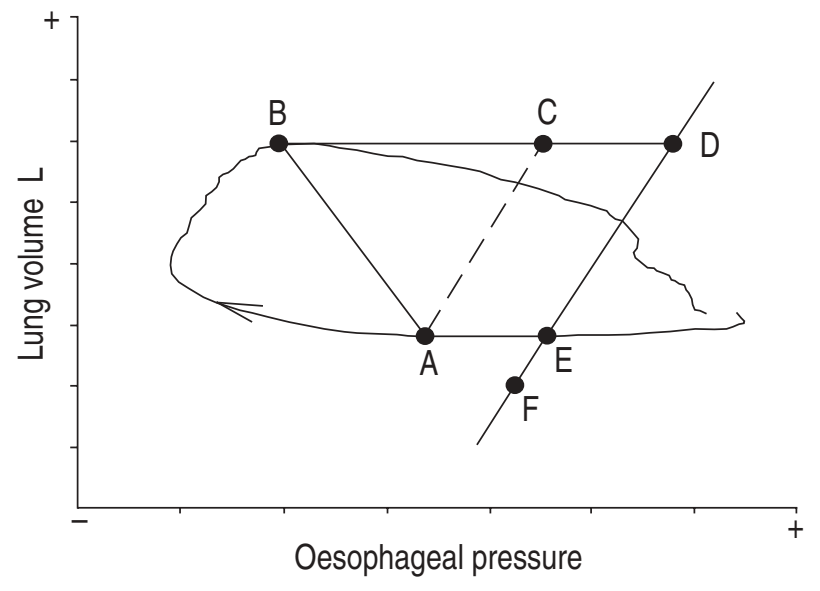

Fig. 1. - Diagrammatic presentation of the partitioning of the elastic work of inspiration during dynamic hyperinflation. Please see text for further explanation.

the static volume-pressure relationship of the chest wall was obtained from the literature, taking the age and sex of each patient into consideration [19]. In order to position the static volume-pressure relationship of the chest wall properly, we first determined the end-expiratory $P_{\text {oes }}$ value during quiet breathing, to represent the chest wall elastic recoil pressure, shown at point $F$ in figure 1 . Then, we positioned the static volume-pressure relationship of the chest wall by passing it through point F. It needs to be pointed out that: firstly, since most of our patients with COPD had dynamic hyperinflation and PEEPi during quiet breathing, $P_{\text {oes }}$ started to fall before inspiratory flow began [20, 21]. End-expiration, therefore, was defined as the point at which $P$ oes began to fall for the next inspiratory effort rather than the beginning of inspiratory flow; secondly, due to dynamic hyperinflation during quiet breathing, the volume at point $\mathrm{F}$ was often already above the relaxation volume $(V \mathrm{r})$; and thirdly, expiratory muscles were active at end-expiration during quiet breathing in some patients with COPD, resulting in elevation of endexpiratory $P$ oes independent of chest wall elasticity [13]. This was confirmed by an expiratory rise in $P$ ga converted to an abrupt inspiratory fall with outward displacement of the abdomen [13]. To circumvent this problem, the Poes value at point $F$ was carefully corrected by subtracting the expiratory rise in $P$ ga whenever applicable, as recently suggested by LESSARD et al. [22]. Figure 2 shows the tracings of expiratory muscle recruitment during quiet breathing and defines the method used to correct the effect of this phenomenon on end-expiratory $P$ oes estimation. Five of our patients displayed the pattern shown in figure 2 during quiet breathing. The mean correction for these patients was $2.1 \mathrm{cmH}_{2} \mathrm{O}$ (range: $0.8-3.6 \mathrm{cmH}_{2} \mathrm{O}$ ).

As shown in figure 1, a clockwise dynamic volumepressure breathing loop during exercise is superimposed on the static volume-pressure relationship of the chest wall. The EELV of this breath, as given by the level of A and E, is above the volume at point $\mathrm{F}$, suggesting dynamic hyperinflation or further dynamic hyperinflation. Points A and B represent the beginning and end of inspiratory flow (zero flow points), respectively. If we assume that inspiratory effort begins from point $\mathrm{E}$, the pressure difference between points E and A represents dynamic PEEPi [23]. The pressure difference between points $\mathrm{D}$ and $\mathrm{B}$ represents the total
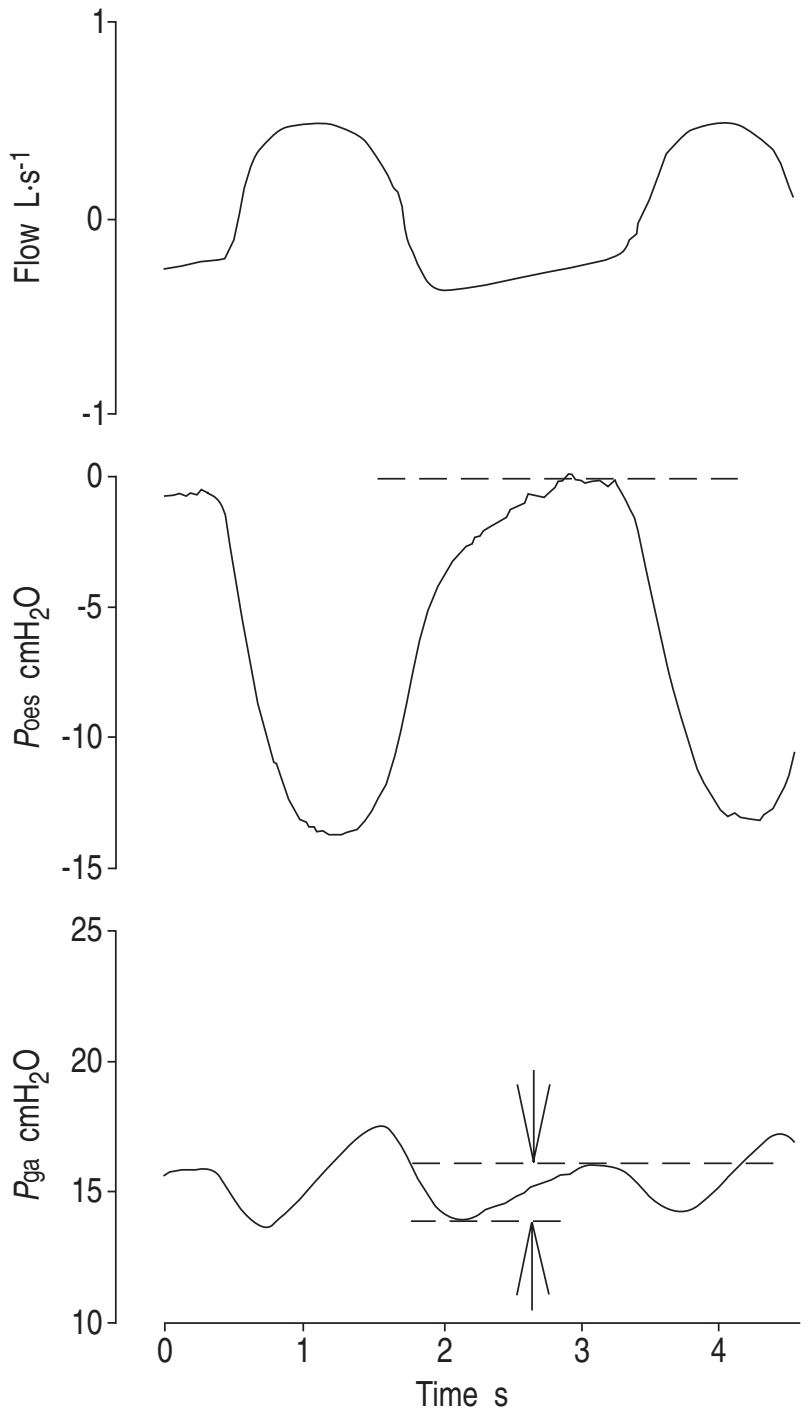

Fig. 2. - Example of flow, oesophageal and gastric pressure ( $P$ oes and $P$ ga, respectively) tracings with expiratory muscle recruitment during quiet breathing. $P$ ga is biphasic with a large rise in inspiration and a small rise in expiration. The latter suggests active expiration. The amount of the expiratory increase in $P$ ga (as shown between the arrows) is subtracted from the Poes baseline, to correct the effect of expiratory muscle contribution.

inspiratory pressure needed for the whole inspiration. The straight line passing points $\mathrm{A}$ and $\mathrm{C}$ (dashed line) is made parallel to the static volume-pressure relationship of the chest wall. Consequently, the total $W_{\mathrm{i}}$ is given by the area enclosed by points A, B, D and E. However, $W_{i}$ can be partitioned into the portion required to overcome PEEPi $\left(W_{\mathrm{i}, P E E P i}\right)$ as expressed by the area enclosed by points $\mathrm{A}$, $\mathrm{C}, \mathrm{D}$ and $\mathrm{E}$, and the portion required to overcome the nonPEEPi elastic load ( $W$ i,nonPEEPi) as given by the area enclosed by points A, B and C. The latter is used to overcome the increase in the total respiratory system elastance during inflation.

The $W$ i,nonPEEPi measured as described above was further compared with the calculated $W$ i,nonPEEPi predicted from the increase in $V \mathrm{~T}$ alone during exercise [24]. As shown in figure $1, W \mathrm{i}$,nonPEEPi is given by the triangle $\mathrm{ABC}$ and can be expressed as $1 / 2 \cdot V \mathrm{~T} \cdot \mathrm{BC}$. Since BC represents the increase in total respiratory system elastic recoil 
pressure during inspiratory inflation, it can be expressed by $V \mathrm{~T} / C \mathrm{rs}$ where $C \mathrm{rs}$ is the compliance of the respiratory system. Thus, assuming linearity, $W$ i,nonPEEPi can be calculated as $1 / 2 \cdot V \mathrm{~T} \cdot V \mathrm{~T} / C_{\mathrm{rs}}$ or $V \mathrm{~T}^{2} / 2 \cdot C$ rs. If $C$ rs is constant, the increase in $W \mathrm{i}$,nonPEEPi during exercise will be proportional to the increase in $V \mathrm{~T}^{2}$. Any discrepancy between the

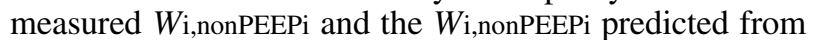
the increase in $V \mathrm{~T}$ alone will therefore indicate the contribution of changes in $C$ rs to $W \mathrm{i}$,nonPEEPi.

Results are presented as mean \pm SEM. Analysis of variance and paired t-test were used, to compare the results under different experimental conditions. A p-value of $<0.05$ was considered to be statistically significant.

\section{Results}

At the symptom limitation, the exercise workload accomplished by the patients was $28 \pm 2.5 \%$ pred. At this level of exercise, $V^{\prime} \mathrm{E}$ was $27.9 \pm 1.8 \mathrm{~L} \cdot \mathrm{min}^{-1}$.

Figure 3 shows the relationship between lung volume $(V \mathrm{~L})$ and $P$ oes at the beginning (open circles) and end of inspiratory flow (closed circles). Therefore, the level of $V \mathrm{~L}$ corresponding to each open and closed circle represents EELV and EILV, respectively for a given condition. Values were obtained during quiet breathing and at different intensities of exercise. In this figure, zero $V \mathrm{~L}$ represents the level of EELV during quiet breathing. During exercise, all patients demonstrated increased EELV suggesting dynamic hyperinflation. Most patients reached the highest EELV and EILV at maximal exercise. From quiet breathing to peak exercise, EELV increased by $0.35 \pm 0.07$ L. This resulted in an increase in dynamic PEEPi from $2.5 \pm 0.4-6.0 \pm 0.7 \mathrm{cmH}_{2} \mathrm{O}(\mathrm{p}<0.0001)$. As shown in figure 3 , the curvilinear aspect of the dynamic $V \mathrm{~L}-P$ oes relationship at zero flow likely reflected the combined effects of increasing curvature of the volume-pressure curve of the lung itself due to increasing volume and decreasing $C \mathrm{~L}$,dyn during exercise. From quiet breathing to peak exercise, $C$ L,dyn significantly decreased from $0.27 \pm 0.04-0.17 \pm 0.02$ $\mathrm{L} \cdot \mathrm{cmH}_{2} \mathrm{O}^{-1}(\mathrm{p}<0.01)$.

Figure 4 shows $W_{\mathrm{i}}, W_{\mathrm{i}, P E E P i}$, and $W \mathrm{i}$,nonPEEPi during quiet breathing and at the first, the middle, and the peak exercise intensity (E1, E2 and E3, respectively). Although all three parameters progressively increased during exercise, the rates of increase in $W \mathrm{i}, \mathrm{PEEPi}$, and $W \mathrm{i}$,nonPEEPi differed. During quiet breathing, $W_{\mathrm{i}, P E E P i}$, and $W_{\mathrm{i}, \text { nonPEEPi }}$ were $1.68 \pm 0.28$ and $3.02 \pm 0.43 \mathrm{~L} \cdot \mathrm{cmH}_{2} \mathrm{O}^{-1}$, respectively, with the former significantly less than the latter $(p<0.05)$. During exercise, $W$ i,PEEPi increased more than $W$ i,nonPEEPi, so that at peak exercise, their values reach $5.34 \pm 0.78$ and $5.10 \pm 0.47 \mathrm{~L} \cdot \mathrm{cmH}_{2} \mathrm{O}^{-1}$, respectively, and were no longer significantly different ( $\mathrm{p}>0.75$ ). Consequently, when $W \mathrm{i}$,PEEPi is expressed as a fraction of $W \mathrm{i}$, the ratio progressively in-

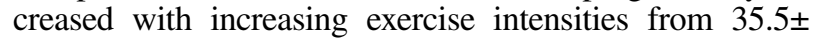
$5.6 \%$ during quiet breathing to $51.0 \pm 3.3 \%$ at peak exercise $(\mathrm{p}<0.05)$.

Figure 5 plots the measured $W$ i,nonPEEPi as a function of the predicted $W \mathrm{i}$,nonPEEPi calculated from the increase in $V \mathrm{~T}$ alone during exercise. Both are expressed as a percentage of the value obtained during quiet breathing. The measured $W$ i,nonPEEPi was slightly but consistently higher than the predicted $W$ i,nonPEEPi. At peak exercise (E3), the discrepancy was $25 \%$.
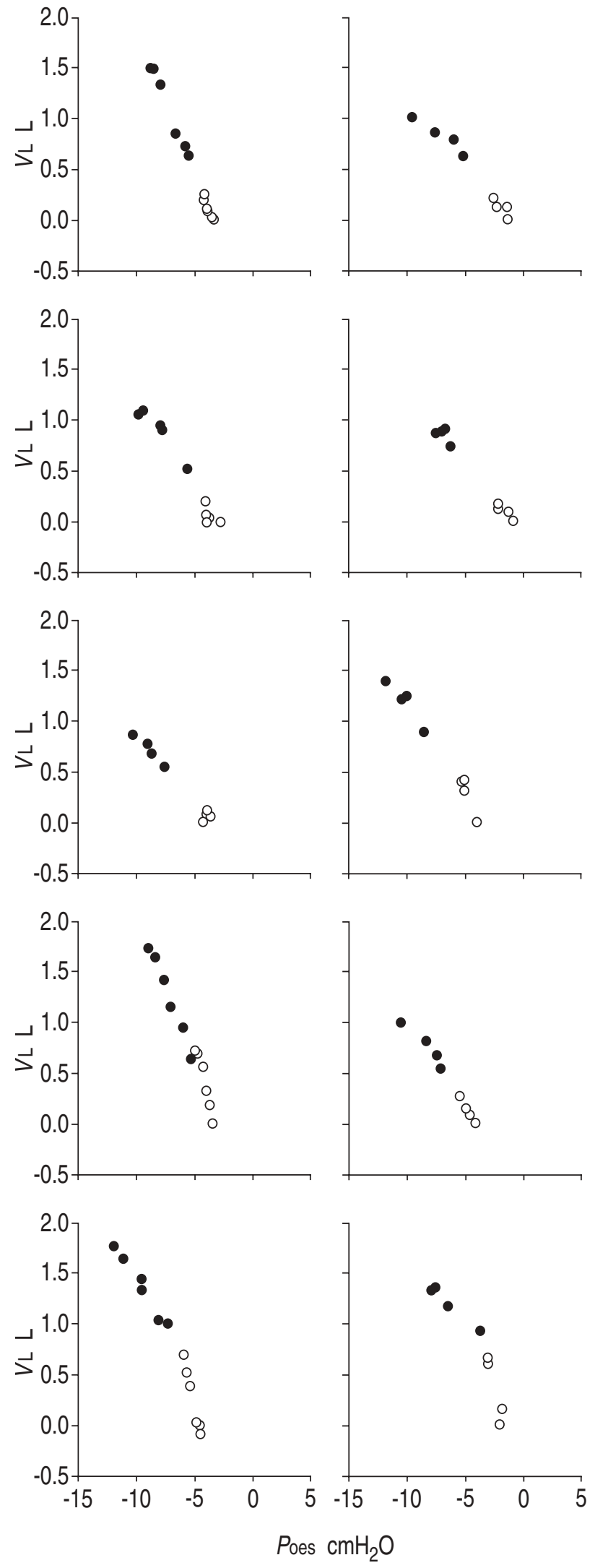

Fig. 3. - The relationship between lung volume ( $V \mathrm{~L})$ and oesophageal pressure (Poes) at the beginning o $)$ and end $(\bullet)$ of inspiratory flow during quiet breathing and at different intensities of exercise in individual patients. Zero $V \mathrm{~L}$ represents the end-expiratory lung volume during quiet breathing. 


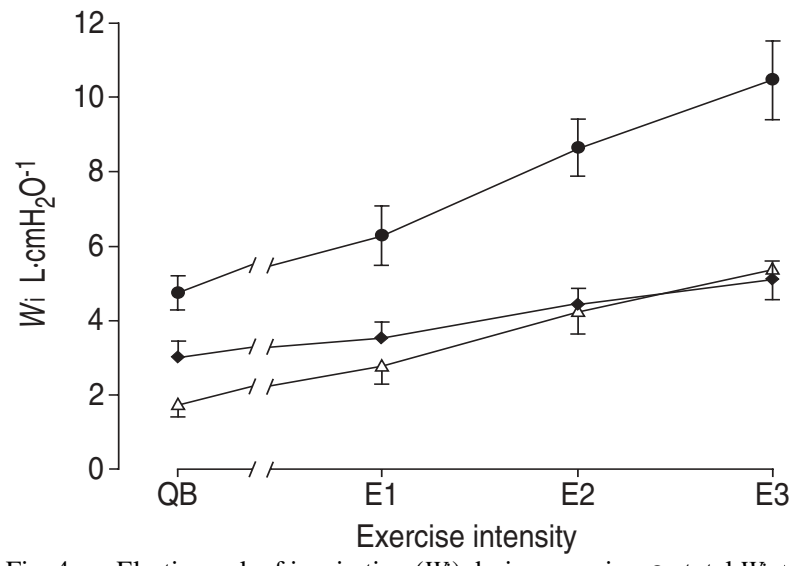

Fig. 4. - Elastic work of inspiration $\left(W_{i}\right)$ during exercise. $\bullet$ : total $W_{i} ; \Delta$ : the work required to overcome intrinsic positive end-expiratory pressure (PEEPi) (Wi,PEEPi); : the work required to overcome nonPEEPi elastic load ( $W \mathrm{i}$,nonPEEPi). QB: quiet breathing; E1, E2 and E3: first, middle and peak exercise intensity.

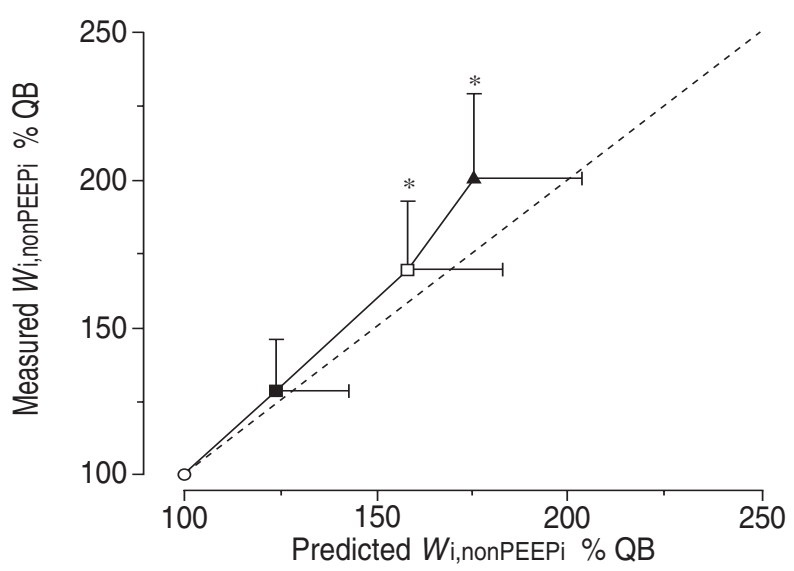

Fig. 5 - The measured elastic work of inspiration $(W \mathrm{i})$ required to overcome the nonintrinsic positive end-expiratory pressure (nonPEEPi) elastic load ( $W$ i,nonPEEPi) plotted against the predicted $W_{i}$,nonPEEPi. Both are expressed as percentage of quiet breathing (QB). --- : the line of identity. $\bigcirc$ : QB; $\mathbf{\square}, \square$ and $\boldsymbol{\Delta}$ : first, middle and peak exercise intensity (E1, E2 and E3, respectively). *: measured Wi,nonPEEPi significantly greater than predicted.

\section{Discussion}

We measured the dynamic $W_{\mathrm{i}}$ in patients with severe COPD during incremental bicycle exercise, until symptom limitation. We partitioned the total $W_{\mathrm{i}}$ into $W \mathrm{i}$,PEEPi and $W$ i,nonPEEPi which corresponded to the work performed to overcome the PEEPi and nonPEEPi elastic load of the respiratory system, respectively. We found that: 1) $W$ i,PEEPi became an increasingly important contributor to $W \mathrm{i}$ as exercise proceeded to the maximum. At exhaustion, $W \mathrm{i}$,PEEPi accounted for over $50 \%$ of total $W_{\mathrm{i}}$ in these patients; and 2) at peak exercise, the measured $W_{i}$,nonPEEPi was $25 \%$ greater than the value predicted from the increase in $V \mathrm{~T}$ alone. This can be explained by a significant decrease in $C \mathrm{~L}$,dyn associated with exercise.

We used the method described by FLEURY et al. [17] to calculate $W$ i while taking into consideration of $\triangle E E L V$ and the PEEPi-imposed inspiratory threshold load [25]. We used the end-expiratory $P$ oes baseline to represent the end-expiratory elastic recoil pressure of the chest wall during quiet breathing, and positioned the predicted static pressure-volume relationship of the chest wall at that point. This procedure has been used by many previous researchers $[17,25,26]$. In addition, we used the method described by LESSARD et al. [22] to correct the effect of expiratory muscle recruitment on determination of endexpiratory chest wall elastic recoil pressure during quiet breathing. It can be seen in figure 1 that once the static chest wall volume-pressure relationship was positioned, all subsequent measurements were referenced to this relationship and additional adjustments for expiratory muscle contribution were not necessary during exercise. However, there are still a number of concerns that need to be addressed. Firstly, end-expiratory $P_{\text {oes }}$ could have changed due to changes in flow resistance independent of inspiratory muscle contribution, which would have influenced the reliability of point $\mathrm{F}$ determination in figure 1 . After carefully checking our signals, we found that at end-expiration, the fall in $P$ oes almost always coincided with the rise in transdiaphragmatic pressure for the subsequent in-spiratory effort during quiet breathing, suggesting that the resistive pressure loss at end-expiration would be reasonably small. This is consistent with recent findings in pati-ents with COPD that during spontaneous breathing, the rapid decrease in $P_{\text {oes }}$ at end-expiration was in phase with the start of the electric activities of both the diaphragm and accessory muscles [22]. Secondly, since we used the predicted volume-pressure relationship of the chest wall as reference of the measurements for each individual, a certain degree of random error was unavoidable due to intersubject variability. We hope that this would be minimized by only reporting and interpreting the group results. Thirdly, it is obvious that the effect of any error of the slope or position of the chest wall volume-pressure curve on calculation of the $W_{\mathrm{i}}$ will be amplified by increasing $V$ T (fig. 1). However, $V$ T only increased from $0.72 \mathrm{~L}$ during quiet breathing to $0.88 \mathrm{~L}$ at maximal exercise. This makes any error of $W$ i or its components to be relatively constant and independent of exercise, and therefore less likely to have significantly influenced the major interpretations of our results based on comparisons between rest and at different levels of exercise.

As has been shown previously [6], in spite of severe expiratory airflow limitation, the increase in EELV in patients with COPD during exercise was modest. At symptom limitation, we found an average increase in EELV of 0.35 L. This, with the small increase in $V \mathrm{~T}$ of $0.16 \mathrm{~L}$, however, leads to a reduction of the inspiratory reserve volume by $0.51 \mathrm{~L}$ or $54 \%$. Meanwhile, $W$ i,PEEPi more than tripled between quiet breathing and peak exercise and accounted for more than $50 \%$ of $W \mathrm{i}$ at exhaustion, while $W_{\mathrm{i} \text {,nonPEEPi }}$ only increased moderately (fig. 4). These results suggest that, in patients with COPD, the increase in $W_{\mathrm{i}}$ during exercise comes mainly from the increase in the magnitude of dynamic hyperinflation. Accordingly, our present work has added evidence to support the notion that dynamic hyperinflation is probably the most important factor contributing to exercise limitation in patients with COPD. In fact, even during quiet breathing, the effect of dynamic hyperinflation could be more significant than ever thought. We observed a dynamic PEEPi of $2.5 \mathrm{cmH}_{2} \mathrm{O}$ in our patients during quiet breathing, a magnitude consistent with other studies $[20,21]$. However, $36 \%$ of $W$ i was required to overcome this "mild" PEEPi. Since respiratory controllers are able to detect very small increases in elastic load and respond to it to adjust ventilatory output [27], we would postulate that the PEEPi we observed at rest 
might be sufficient to affect the control of spontaneous quiet breathing in patients with stable COPD.

In this study, we assumed that dynamic compliance of the chest wall $\left(C_{\mathrm{W}}, \mathrm{dyn}\right)$ during exercise is constant and equal to its static compliance. This assumption may not be true. Our calculation of $W \mathrm{i}$,nonPEEPi did not include influences from a possible change in $C_{\mathrm{w}, \mathrm{dyn}}$ [28], because we could not measure it in the present study. In other words, our results, showing that part of the increase in $W \mathrm{i}$,nonPEEPi during exercise cannot be explained by the increase in $V \mathrm{~T}$ alone (fig. 5), were entirely attributable to changes in lung mechanics. As has been described previously [10], we sho-wed a significant decrease in $C$, dyn in our patients during exercise. This may be largely due to a significant frequ-ency dependence of $C \mathrm{~L}$,dyn in patients with COPD [11] and, probably to a less extent, due to a decrease in the static lung compliance ( $C \mathrm{~L}$,stat) at increased operating lung volume during dynamic hyperinflation. To what extent the latter contributed to the observed decrease in $C \mathrm{~L}$,dyn in our patientsisunknownMACKLEMandBECKLAKF 14 /andSTUBBING et al. [10] have shown that in patients with airway obstruction, the static pressure-volume relationship of the lung $(C \mathrm{~L}$,stat) was linear over a large part of the entire inspiratory capacity because of the loss of lung elastic recoil. Therefore, the contribution of the fall in $C \mathrm{~L}$,stat to the observed decrease in $C \mathrm{~L}$,dyn under our experimental conditions would have been small. Since the predicted $W \mathrm{i}$,nonPEEPi was calculated by assuming a constant respiratory system compliance, and the measured $W \mathrm{i}$,nonPEEPi was calculated by assuming a constant chest wall compliance, the discrepancy between the measured and predicted $W \mathrm{i}$,nonPEEPi (fig. 5) was thus the direct consequence of the observed decrease in $C \mathrm{~L}$,dyn during exercise.

In summary, in patients with chronic obstructive pulmonary disease exercising to symptom limitation, dynamic hyperinflation is a major factor contributing to the increase in the elastic work of inspiration, while increasing tidal volume and decreasing the dynamic compliance of the lung during exercise plays a less important role. Therefore, without appropriate intervention for dynamic hyperinflation, the exercise limitation of these patients can hardly be improved.

\section{References}

1. Younes M, Kivinen G. Respiratory mechanics and breathing pattern during and following maximal exercise. $J$ Appl Physiol 1984; 57: 1773-1782.

2. Cha EJ, Sedlock D, Yamashiro SM. Changes in lung volume and breathing pattern during exercise and $\mathrm{CO}_{2}$ inhalation in humans. J Appl Physiol 1987; 62: 1544-1550.

3. Henke KG, Sharratt M, Pegelow D, Dempsey JA. Regulation of end-expiratory lung volume during exercise. $J$ Appl Physiol 1988; 64: 135-146.

4. Younes M. Determinants of thoracic excursions during exercise. In: Whipp BJ, Wasserman K, eds. Exercise: Pulmonary Physiology and Pathophysiology (Lung Biology in Health and Disease, Vol. 52), 1st ed., New York, Marcel Dekker, Inc., 1991; pp. 1-65.

5. Dodd DS, Brancatisano T, Engel LA. Chest wall mechanics during exercise in patients with severe chronic airflow obstruction. Am Rev Respir Dis 1984; 129: 33-38.

6. O'Donnell DE, Webb KA. Exertional breathlessness in patients with chronic airflow limitation. Am Rev Respir Dis 1993; 148: 1351-1357.

7. Belman MJ, Botnick WC, Shin JM. Inhaled bronchodilators reduce dynamic hyperinflation during exercise in patients with chronic obstructive pulmonary disease. Am J Respir Crit Care Med 1996; 153: 967-975.
8. O'Donnell DE, Bertley JC, Chau LKL, Webb KA. Qualitative aspects of exertional breathlessness in chronic airflow limitation: pathophysiologic mechanisms. Am J Respir Crit Care Med 1997; 155: 109-115.

9. Rossi A, Polese G, Brandi G. Dynamic hyperinflation. In: Marini JJ, Roussos C, eds: Ventilatory Failure. Vol. 15, Berlin, Springer-Verlag, 1991; pp. 199-218.

10. Stubbing DG, Pengelly LD, Morse JC, Jones NL. Pulmonary mechanics during exercise in subjects with chronic airflow obstruction. $J$ Appl Physiol 1980; 49: 511-515.

11. Pride NB, Milic-Emili J. Lung mechanics. In: Calverly P, Pride N, eds. Chronic Obstructive Pulmonary Disease. 1st ed. London, Chapman \& Hall, 1995; pp. 135-160.

12. Ninane V, Rypens F, Yernault JC, De Troyer A. Abdominal muscle use during breathing in patients with chronic airflow obstruction. Am Rev Respir Dis 1992; 146: 1621.

13. Ninane V, Yernault JC, De Troyer A. Intrinsic PEEP in patients with chronic obstructive pulmonary disease. Am Rev Respir Dis 1993; 148: 1037-1042.

14. Macklem PT, Becklake MR. The relationship between the mechanical and diffusing properties of the lung in health and disease. Am Rev Respir Dis 1963; 87: 47-56.

15. Campbell EJM. The respiratory muscles and the mechanics of breathing. London, Lloyd-Luke, 1958.

16. Sharp JT, Van Lith P, Nuchprayoon CV, Briney R, Johnson FN. The thorax in chronic obstructive lung disease. Am J Med 1968; 44: 39-46.

17. Fleury B, Murciano D, Talamo C, Aubier M, Pariente R, Milic-Emili J. Work of breathing in patients with chronic obstructive pulmonary disease in acute respiratory failure. Am Rev RespirDis 1985; 131: 822-827.

18. Guerin C, Coussa ML, Eissa NT, et al. Lung and chest wall mechanics in mechanically ventilated COPD patients. J Appl Physiol 1993; 74: 1570-1580.

19. Estenne M, Yernault JC, De Troyer A. Rib cage and diaphragm-abdomen compliance in humans: effects of age and posture. J Appl Physiol 1985; 59: 1842-1848.

20. Haluszka J, Chartrand DA, Grassino AE, Milic-Emili J. Intrinsic PEEP and arterial PCO2 in stable patients with chronic obstructive pulmonary disease. Am Rev Respir Dis 1990; 141: 1194-1197.

21. Vecchio LD, Polese G, Rossi R, Rossi A. "Intrinsic" positive end-expiratory pressure in stable patients with chronic obstructive pulmonary disease. Eur Respir J 1990; 3: 74-80.

22. Lessard MR, Lofaso F, Brochard L. Expiratory muscle activity increases intrinsic positive end-expiratory pressure independently of dynamic hyperinflation in mechanically ventilated patients. Am J Respir Crit Care Med 1995; 151: 562-569.

23. Yan S, Kayser B, Tobiasz M, Sliwinski P. Comparison of static and dynamic intrinsic positive end-expiratory pressure using the Campbell diagram. Am J Respir Crit Care Med 1996; 154: 938-944.

24. Yan S, Sliwinski P, Gauthier AP, Lichros I, Zakynthinos S, Macklem PT. Effect of global inspiratory muscle fatigue on ventilatory and respiratory muscle responses to CO. J Appl Physiol 1993; 75: 1371-1377.

25. Lougheed MD, Webb KA, O'Donnell DE. Breathlessness during induced lung hyperinflation in asthma: the role of the inspiratory threshold load. Am J Respir Crit Care Med 1995; 152: 911-920.

26. Martin JG, Shore S, Engel LA. Effect of continuous positive airway pressure on respiratory mechanics and pattern of breathing in induced asthma. Am Rev Respir Dis 1982; 126: 812-817.

27. Puddy A, Younes M. Effect of slowly increasing elastic load on breathing in conscious humans. J Appl Physiol 1991; 70: 1277-1283.

28. D'Angelo E, Robatto FM, Calderini E, et al. Pulmonary and chest wall mechanics in anesthetized paralyzed humans. J Appl Physiol 1991; 70: 2602-2610. 